IRA-International Journal of Education \&

Multidisciplinary Studies

ISSN 2455-2526; Vol.17, Issue o3 (Q3, 2021)

Pg. no. 177-185.

IRA Academico Research

\title{
A Study on Path of Rural Teachers Helping the Inheritance of Vernacular Culture in China
}

\author{
Ji Li (iD) \\ College of Education and Sports, Yangtze University, Jingzhou, Hubei, 434000, P.R. China.
}

Type of Work: Peer Reviewed.

DOI: 10.21013/jems.v17.n3.pg

DOI URL: https://dx.doi.org/10.21013/jems.v17.n3.p9

\begin{abstract}
Li, J.. (2021). A Study on Path of Rural Teachers Helping the Inheritance of Vernacular Culture in China. IRA-International Journal of Education \& Multidisciplinary Studies (ISSN 2455-2526), 17(3), 177-185. DOl: https://dx.doi.org/10.21013/jems.v17.n3.pg
\end{abstract}

(C) IRA Academico Research.

(c) EY-NC This work is licensed under a Creative Commons Attribution-NonCommercial 4.0 International License subject to a proper citation to the publication source of the work.

Disclaimer: The scholarly papers as reviewed and published by IRA Academico Research are the views and opinions of their respective authors and are not the views or opinions of IRA Academico Research. IRA Academico Research disclaims any harm or loss caused due to the published content to any party.

IRA Academico Research is an institutional publisher member of Publishers International Linking Association Inc. (PILA-CrossRef), USA. IRA Academico Research is an institutional signatory to the Budapest Open Access Initiative. Hungary advocating the open access of scientific and scholarly knowledge. IRA Academico Research is a registered content provider under Open Access Initiative Protocol for Metadata Harvesting (OAI-PMH).

The journal is indexed \& included in WorldCat Discovery Service (USA), CrossRef Metadata Search (USA), WorldCat (USA), OCLC (USA), Open J-Gate (India), EZB (Germany) Scilit (Switzerland), Airiti (China), Bielefeld Academic Search Engine (BASE) of Bielefeld University, Germany, PKP Index of Simon Fraser University, Canada.

Ji Li (iD) /0000-0002-7732-7330

Funding: This paper is a part of the research results of the project "A study on the path of inheriting and promoting Chinese traditional culture in compulsory education schools". 


\begin{abstract}
Vernacular culture is the root of Chinese culture, in essence, so the inheritance of vernacular culture is crucial. Rural teachers are the "rural talents" in rural areas and have been playing various roles as cultural inheritors, protectors and leaders. The cultural responsibilities of rural teachers in the new era face many difficulties: the lack of vernacular cultural literacy of rural teachers, the "urban orientation" of rural education, the backward ideology of rural parents, and the lack of funds. Under the call of rural cultural revitalization, rural teachers should re-erect the banner of cultural inheritance and contribute to rural cultural revitalization by focusing on cultivating rural teachers' local cultural literacy, developing school-based cultural curriculum and compiling local teaching materials, collaborating with village schools and making use of the Internet to promote the inheritance and development of vernacular culture.
\end{abstract}

Keywords: Rural teachers, Vernacular culture, Culture inheritance, Paths

Education has the function of cultural inheritance. Rural teachers, as educators in rural areas, take the responsibility for inheriting and developing vernacular culture while teaching and coaching people. They not only inherited the vernacular culture themselves but also carefully nurtured generations of inheritors so that the vernacular culture can live on and on. It is only with the rapid spread of urbanization and urbanization that the value and charm of vernacular culture have been submerged by modern urban culture, and vernacular culture has gradually fallen into decline. The countryside is the cradle of Chinese civilization. As Liang Shuming pointed out in his Theory of Countryside Construction, "Chinese society is based on the countryside; all culture, for the most part, comes from the countryside and is set up for the countryside - legal system, rituals, commerce and industry, and so on"( Liang,2006).

Therefore, the inheritance and development of vernacular culture is of crucial importance and is closely associated with every Chinese person. In 2020, the Ministry of Education and six other departments recognized in the Opinions on Strengthening the Rural Teacher Corps in the New Era that we should pay attention to the role of rural teachers in demonstrating and leading new villagers, shaping a new era of the prosperous countryside, and promoting the revitalization of vernacular culture (Ministry of Education and other six departments, 2020). The cultural responsibility of rural teachers is clearly given in the form of a document. As intellectuals in rural society, rural teachers should consciously shoulder the responsibility of rebuilding the rural cultural order.

\title{
1. The Cultural Role Played by Rural Teachers
}

As intellectuals in rural areas, rural teachers are veritable "ambassadors of vernacular culture". They combine many roles, being the inheritors of vernacular culture, the leaders of advanced vernacular culture, and the protectors of vernacular culture.

\subsection{The Inheritor of the Vernacular Culture}

First of all, rural teachers try hard to master the vernacular culture so as to achieve cultural inheritance. Then, they pass on their knowledge of vernacular culture to their students or others in various ways in the process of propagating the doctrine, imparting professional knowledge, and resolving doubts. With the slow growth and development of rural students and the construction and generation of cultural knowledge, the inheritance and innovation of vernacular culture will be realized (Yi \& Zhang, 2020) Although the cultural heritage of rural areas also relies on the personal instruction of local residents and a 
few historical materials, the scope of the heritage is small (usually the immediate family members), the content is fragmented, lacking in systematization, and has a strong subjective and mythical colouring. Rural teachers can just make up for those shortcomings, and there is strong subjective and mythical colouring. Only through the joint efforts of the village teachers and the local villagers can the vernacular culture endure and spread forever.

\subsection{The Leader of Advanced Vernacular Culture}

As far as the characteristics of teachers profession are concerned, the rural teachers themselves play an exemplary role, and their behaviours can effectively spread the excellent traditional culture (Gu, 2019). China is rich in land and resources, and its vernacular culture is extremely rich. Excellent vernacular culture can promote the development of rural society, but the dregs in vernacular culture will hinder the development of rural society. Rural areas still retain a lot of cultural dregs, such as turning to the gods instead of doctors when they are sick. Therefore, not all vernacular culture is the essence of all worthy to be passed on. But rural residents have a low level of education. They cannot distinguish between what is good and what is bad. So, they need people with knowledge, vision, new methods and new technologies to guide and lead them constantly. There is no doubt that rural teachers are the people who meet those requirements. In the face of diverse vernacular cultures, rural teachers can judge and choose objectively and rationally by their knowledge literacy, so as to classify and sort out those excellent vernacular cultures (Du et al., 2015). Of course, while inheriting the excellent vernacular culture, rural teachers also continue to develop and innovate the vernacular culture, injecting into the vernacular culture, thus making the vernacular culture more diversified and more in line with the trend of contemporary consciousness.

\subsection{The Protector of Vernacular Culture}

Rural teachers play an important role in the protection of vernacular culture and are the protectors of vernacular culture. First, rural teachers can discover the potential vernacular culture. There are many invisible or potential vernacular cultures in rural areas that are difficult for the villagers to discover, let alone to protect. Because of their cultural responsibilities and extensive knowledge and vision, rural teachers have a certain degree of sensitivity to vernacular culture and often discover a vernacular culture that the villagers have not discovered or explored the potential value of vernacular culture, and carry it forward to avoid the danger of its premature extinction. Secondly, rural teachers will protect the existing vernacular culture. Rural teachers either propagandize the knowledge of culture and law to enhance the awareness of protecting the vernacular culture. Or participate in the compilation of vernacular culture books, the construction of vernacular culture centers and the promotion of vernacular culture products, to a certain extent, these acts have protected the vernacular culture.

\section{The Difficulties Faced by Rural Teachers in Inheriting Vernacular Culture}

\subsection{Rural Teachers: Lack of Vernacular Cultural Literacy}

Rural teachers are responsible for cultural inheritance and should be the cultural elite in rural areas. However, from the actual investigation, a considerable number of rural teachers' local cultural literacy cannot fulfil the responsibility of cultural inheritance, whether at the level of subjective awareness, knowledge or skill level, which needs to be improved.

First, the awareness of the cultural heritage of rural teachers is weak. Since ancient times, rural teachers have been cultural people rooted in vernacular culture and rural society. They are rural talents 
who grew up with specific habits and values, with strong local emotions and are familiar with the moral and traditional customs and manners of rural society (Yu et al., 2020). They used to be the main force in inheriting vernacular culture. However, nowadays, most rural teachers have no spiritual attachment to the countryside and no emotion for the vernacular culture because they are not native to the countryside and work in the countryside and live in the city. Some of them even just use their current professional experience as a "capital" and "springboard" to be among urban life. Related studies show that $65.7 \%$ percent of rural teachers want to transfer to urban teaching (Cao \& Zhang, 2019). Therefore, they pay less attention to the inheritance of vernacular culture and lack the sense of responsibility to actively inherit vernacular culture. They are usually reluctant to spend too much effort in organizing cultural courses and cultural activities that do not conform to the specified teaching tasks. As one teacher said, "These students are local people, they must know some of the vernacular cultures, what they need to learn is something advanced. We don't want to take the time to do those things because our school has few teachers and the curriculum is very stressful." It can be seen that some rural teachers have a low sense of local cultural identity and are intentionally or unintentionally shirking the responsibility of passing on their culture. Second, rural teachers have poor knowledge of vernacular culture. Vernacular knowledge is the core element of vernacular culture and is the basis for inheriting and revitalizing vernacular culture (Yi \& Ma, 2021). As intellectuals and educators in rural areas, the necessary vernacular knowledge should be a prerequisite for every rural teacher to carry out teaching and inherit vernacular culture, so every rural teacher should be well versed in vernacular culture. The new generation of rural teachers, however, know little about the vernacular culture. For some reason, when they become rural teachers, they do not actively seek knowledge and integrate into the local village. Third, teaching methods are backward. As a whole, the teaching methods of rural teachers lack flexibility. Although the educational resources in the countryside cannot compare with those in the city, there are abundant resources for conducting cultural courses, but many teachers, in order to avoid risks, mainly convey culture lessons orally in closed classrooms, and seldom lead students out of the school to observe and research. In the boring classroom atmosphere, it is difficult to stimulate students' interest in vernacular culture. Students show the characteristics of "three no-learning" i.e., learning is uninteresting, boring, and useless. In addition, the overall level of electronic information literacy of rural teachers is not high, especially the middle-aged and elderly teachers in rural areas who are unfamiliar with computers and multimedia devices.

\subsection{Rural Schools: Urban-oriented Rural Education System}

Under the guidance of the National Unified Curriculum Program, the rural schools in our country keep consistent with the urban schools from the curriculum setting to the contents of the teaching materials. Rural schools basically use the Ministry of Education's version of the textbook, and they also strive to "open up" the national curriculum as required. The same examination system is used in both urban and rural areas nationwide. And the same examination system is used in both urban and rural areas throughout the country. The consequence of this "urban-oriented" education system is that rural schools no longer emphasize cultural development. Rural schools only teach textbook knowledge and aim to help students take exams. On weekdays, the daily school teaching is not relevant to the village, the students' learning content has no connection with their daily life and the village, the inheritance of village culture is not related to school education, and the rural school becomes an isolated island in the village. Rural education simply transmits and disseminates urban-centred knowledge systems and cultural civilization. In this urban culture-oriented educational environment, the bloodline between rural schools and 
vernacular culture has been severed to some extent. As a result, rural education is losing its vernacular culture.

\subsection{Rural residents: Backward Thinking and Shallow Cultural Values}

For a long time, rural areas have held the idea that urban areas represent advancement and affluence, while rural areas represent backwardness and poverty. This dichotomy is deep-rooted in rural areas. As some surveys show, the older villagers' awareness of the value of vernacular culture is mostly at the economic level, because vernacular culture can attract foreign tourists and increase revenue for local economic development. Vernacular culture is gradually considered as "old ideas" and "old concepts" that are "out of date and no longer useful" (Suo, 2018). Therefore, children and parents are happy to pursue the "advanced" urban culture to become the carp that jumped over the dragon gate and went out of the countryside to embrace the prosperous city. Therefore, some rural cultural activities are "uncouth" in the eyes of rural students and parents, which is a manifestation of rural teachers' inaction. They may even be obstructed on various grounds such as delaying the children's studies, being unlucky, and clashing with the gods.

In addition, the relatively insufficient investment in rural education is also one of the predicaments that prevent rural teachers from inheriting vernacular culture. Funds, teachers, equipment and other resources are the basis for the development of education. When the foundations are weakened, education will become the embarrassment of "Make bricks without straw" (Wang \& Sun, 2021). According to the 2019 Statistical Bulletin on the Implementation of National Education Expenditure, the national average general public budget education expenditure per student for education in general elementary school was RMB 11,197.33 and RMB 10,681.34 in rural areas; the national average junior high school was RMB $16,009.43$ and RMB 14,542.23 in rural areas. In terms of the general public budget public expenditure per student in education, the national average elementary school is RMB 2,843.79 and the rural area is RMB 2,548.73; the national average junior high school is RMB 4,012.45 and the rural area is RMB 3,513.97 (Ministry of Finance of the People's Republic of China, 2020). The investment in education in rural areas is lower than the national average, and thus it can be seen that the gap with urban areas is even greater. Due to the lack of resources and lack of funds many cultural activities and cultural programs are stifled in the cradle, and the motivation and incentive of rural teachers are discouraged.

\section{The Path of Rural Teachers' Inheritance of Vernacular Culture}

\subsection{Improving Vernacular Cultural Literacy and Establishing Cultural Consciousness}

To a certain extent, the local cultural literacy of rural teachers determines the revitalization of vernacular culture. In order to better fulfil the mission of guarding and passing on vernacular culture, rural teachers should continuously enhance their cultural literacy and establish a cultural consciousness of their vernacular culture (Yi \& Zhang, 2020). Cultural consciousness refers to an individual's understanding, identification and attachment to the culture in which he or she lives. As for the rural teachers, the vernacular culture consciousness is the basis for them to protect and inherit the vernacular culture, and it is the motivation for them to actively transform rural society ( $\mathrm{Wu} \&$ Yang, 2008). Therefore, rural teachers have to learn vernacular culture through various channels. But, cultural knowledge is different from other knowledge, which is slowly accumulated in a long productive life, and some cultures cannot be expressed in words; therefore, rural teachers must also integrate into rural life in order to acquire vernacular culture with roots. Then, as a teacher, one should not only "Know what it is" but also "Know why it is there". Rural Teachers' understanding of vernacular cultural knowledge can not only remain on 
the surface but also need to research deeply so that they can fully understand the culture and eventually internalize it. Finally, rural teachers should see the unique charm of vernacular culture and "Love" vernacular culture, because only love can do it wholeheartedly. Many rural teachers move between the city and the countryside, forming a state of physical and mental separation, with a very weak sense of regional identity and cultural belonging. So, it is particularly important to love the local-color culture and produce spirit conversion. That is, from the heart that "I belong to this land." When they feel proud of their status as rural teachers, they develop a love for the vernacular culture. In their daily teaching and life, they will pass on this emotional satisfaction to the children in a timely, so that the latter will remember their homesickness, see their hope and hold their happiness, and become competent inheritors of the vernacular culture (Wang \& Sun, 2021).

\subsection{Developing School-based Cultural Curriculum and Compiling Rural Teaching Materials}

Each village in rural areas of China has its own style (Wang, 2016). As the saying goes, "the wind is different in ten miles, and the customs are different in a hundred miles."At present, China has a three-tier curriculum management system: national, local, and school. Nevertheless, the corresponding national and local curricula are generally difficult to care for every region in the countryside, and it is impossible to focus on each individual learner. The school-based curriculum and vernacular teaching materials can make up for this deficiency to a certain extent. Getting vernacular culture into school education, developing vernacular culture curriculum and preparing vernacular teaching materials are the basic ways and means to pass on vernacular culture and civilization. The development of local teaching materials and vernacular culture curriculum should make full use of local resources. Rural natural resources are unique educational resources in rural areas. In the absence of other educational resources, rural natural resources are undoubtedly the richest and easiest resources to utilize. Teachers and students can use heaven and earth as their classroom and all things as their teachers, so that all resources around them can become teaching resources for children, such as grains and vegetables, festivals, mountains and rivers, folk customs, monuments and cultural relics, language and costumes, and so on. However, while highlighting regional characteristics, the curriculum of vernacular culture should avoid going to the extreme of "Regionalism" or paying too much attention to national, regional and local features while ignoring modernity and science, so that too much emphasis is placed on cultural inheritance at the expense of cultural intermingling (Hai et al., 2009). We should put people at the center of our education, respect people, teachers and students, and consider the cultural contents that are most vital and deeply rooted in people's hearts ( Hai et al., 2009).

In addition, whether or not the cultural curriculum arouses learners' interest and curiosity directly determines the effectiveness of vernacular culture inheritance. Therefore, rural teachers also need to improve their teaching skills, less empty and boring preaching, and more fun and exploration, so as to present the effect of the vernacular materials and school-based cultural curriculum in a better way. Let the children go out of school to work in tea gardens, farms and bacchanalian gardens; to study in county museums; to listen to the wind and rain, observe plants and animals; to interview the elderly left behind, etc.

\subsection{Integration and Collaboration between Rural Communities and Schools: "Go out", "Come in"}

Rural society nurtures vernacular culture, so the inheritance and development of vernacular culture cannot be separated from rural society either. Rural teachers must break the spatial isolation between schools and rural society, so that rural communities and schools can become one and inherit vernacular 
culture together in synergy and cooperation.

On the one hand, rural teachers should "go out". The so-called "going out" means that rural teachers should go out of school, go into villages and return to rural life. Rural teachers should take advantage of their knowledge and participate in the reconstruction of vernacular culture. Through lectures, cultural exchange platforms, and rural cultural activities, they can publicize and popularize vernacular culture and give villagers a more comprehensive and thorough understanding of their culture. At the same time, rural teachers play an important role in improving the overall cultural quality and spiritual cultivation of villagers. Therefore, rural teachers should also convey new cultural ideas to local villagers, promote progressive concepts and healthy lifestyles, guide villagers to abandon stereotypes and improve their scientific and cultural literacy. This will enable people to truly respect the land, return to themselves and view vernacular culture correctly in the midst of the profound accumulation of farming civilization. On the other hand, rural teachers should also "invite" outstanding residents and excellent vernacular culture into campuses. However, some scholars have found that knowledge related to agriculture, farming and livestock production is not taught in rural schools, and some folk arts or local cultural heritage are rarely included in rural school classrooms; Those artists who created the aforementioned folk arts and vernacular culture were hardly allowed to be on the podium of schools (Weng, 2009). Such a phenomenon is very disadvantageous to the inheritance and development of the vernacular culture, because those who have prestige, folk artists and inheritors are the rural elites who are born and grew up here, and no one knows the vernacular culture better than them. Therefore, rural teachers should let professional people do professional things, respect and reuse them, and let them enter the campus, stand on the podium, and work together with teachers and students to build the vernacular culture.

\subsection{Relying on the Internet to Promote Cultural Heritage}

The dissemination and inheritance of culture in rural areas is mainly based on oral language and writing, but both are limited by time and space. Nowadays, the Internet has brought convenience to people, and it has completely broken the limitation of time and space, opening up a convenient and fast high-speed tunnel for a cultural inheritance, making the content of human cultural inheritance richer, more visual and audio, and more intuitive, and facilitating communication and interaction among all people in learning traditional culture. (Sun, 2018). In the 21st century, the Internet has become the most widespread and convenient communication channel. China is a country suitable for using the Internet for cultural inheritance. CNNIC released the 47th Statistical Report on the Development Status of China's Internet in Beijing, showing that as of December 2020, the size of China's Internet users reached 989 million and the Internet penetration rate reached 70.4\% (China Internet Network Information Center, 2021). The value of vernacular culture has been gradually forgotten and neglected, and in this era of Internet prevalence, the development of China's Internet precisely provides a new opportunity for the dissemination and popularization of vernacular culture. In such an environment, rural teachers should follow the pace of the times, firmly grasp the opportunity, and rely on the powerful dissemination and storage functions of the Internet to help the inheritance of vernacular culture. The combination of internet and vernacular culture forms the pattern of "Internet + vernacular culture". Rural teachers should learn Internet knowledge, innovate teaching forms, and use major media to increase the publicity of vernacular culture so that more people will know and love it. For example, rural teachers can record high-quality vernacular culture courses and upload them to the Internet platform, or become vernacular culture anchors. This is a great way to pass on and promote vernacular culture, and also to gain economic benefits.

Finally, the heritage and development of vernacular culture is a long way to go, and it is difficult to 
accomplish this if we rely on individual teachers alone. After all, a single tree cannot make a forest. Therefore, the relevant government departments should formulate "vernacular" oriented policies to support it. For example, relevant departments should increase the financial investment in rural cultural education; pay attention to the guidance and training of rural teachers' local cultural literacy, such as incorporating local cultural knowledge into the normal education and pre-service training; And also can build professional standards for rural teachers and incorporate vernacular culture into the assessment; of course, we should also give rural teachers generous salary and welfare benefits and honorary recognition, so that the rural teachers can become an enviable profession.

\section{References}

[1]. Liang, S.M. (2006).Theory of Rural Construction. Shanghai: Shanghai People's Publishing House.

[2]. Ministry of Education and other six departments. (2020).Ministry of Education and other six d epartments on strengthening the new era Opinions on the Construction of Rural Teachers' Tea m. http://www.moe.gov.cn/jyb_xwfb/gzdt_gzdt/s5987/202009/t20200904_485110.html.

[3]. Yi, H.J., \& Zhang, Y. (2020).The mission of rural teachers in the reconstruction of rural cultural order. Educational Culture Forum, 12(01), 94-98.

[4]. Gu, Y.J. (2019). Exploration of the path of rural teachers helping rural cultural inheritance in rural revitalization. Educational Theory and Practice, 39(13), 47-50.

[5]. Du, L.J., Jia Z.G., \& Zhang, B. (2015). The cultural mission of rural teachers in a cultural knowledge-based perspective. Journal of Changshu University of Technology, 1, 86 - 90.

[6]. Yu, F.Y., Ren, S.H., Wisdom, L., Ma, H.L., \& Li, C.L.(2020). Several orientations for promoting the modernization of China's rural education in the new era (pencil talk) [J]. Journal of Jishou University (Social Science Edition), 41(06), 25-37.

[7]. Cao, E.L., \& Zhang, L.C. (2019).The decline and reshaping of rural teachers' "cultural mission" in the new era. Xinjiang Social Science, 3, 86-91.

[8]. Yi, J., \& Ma, F. (2021) The realistic representation of the new generation of rural teachers' lack of vernacular culture and the strategy of reshaping it. Contemporary Education Science, 5, 72-79.

[9]. Suo, X.X. (2018).Re-conceptualization of the value of vernacular culture under the strategy of rural revitalization. Guizhou Social Science, 1,4-10.

[10]. Wang, L., \& Sun, R.F. (2021).The responsibility, dilemma and the way forward for rural teachers to inherit vernacular culture in the context of rural revitalization. Contemporary Teacher Education, 14(02), 24-30.

[11]. Ministry of Finance of the People's Republic of China. (2020). Statistical Bulletin on the I mplementation of National Education Expenditure in 2019. http://www.mof.gov.cn/zhengwuxi nxi/caizhengxinwen/202011/t20201104_3616607.html.

[12]. Yi, H.J.,\& Zhang, Y. (2020).The mission of rural teachers in the reconstruction of rural cultural order. Educational Culture Forum, 12(01), 94-98.

[13]. Wu, Z.H., \& Yang, W.A. (2008).The Paradox of Value Choice of Rural Education and its Dissolution. Education Development Research, (Z1), 52 -57.

[14]. Wang, L., \& Sun, R.F. (2021).The responsibility, dilemma and the way forward for rural teachers to inherit vernacular culture in the context of rural revitalization. Contemporary Teacher Education, 14(02), 24-30.

[15]. Wang, L. (2016). The inheritance of village culture and the mission of village schools. Journal of Education Science of Hunan Normal University, 15(06), 26-32. 
[16]. Hai, L., Ba, Z.L., \& Li, H.T. (2009). Valuing local knowledge and inheriting national culture--a review of the seminar on inheriting local knowledge and school-based curriculum development in China. Journal of Guangxi University for Nationalities (Philosophy and Social Science Edition), 31(06), 87-90+201+204.

[17]. Weng, N.Q. (2009).Rural Education in the Village Perspective-A Case Study of Four Villages in Southwest China. Beijing: Social Science Literature Press.

[18]. Sun, X.J. (2018).Research on the heritage and development of Chinese traditional culture in the context of "Internet+". [Master's thesis, Shenyang Normal University].CNKI Database.

[19]. China Internet Network Information Center. (2021).The $47^{\text {th }}$ China Statistical Report on Inte rnet Development. http://www.cnnic.cn/hlwfzyj/hlwxzbg/hlwtjbg/202102/t20210203_71361.html. 